\title{
Comparison of 3D Coral Photogrammetry and Coral Video Transect for Coral Lifeform Analysis Using Low-cost Underwater Action Camera
}

\author{
Zuhairi Bin Ahmad ${ }^{1, *}$, Muhammad Idzham Helmi Bin Mohd Jinah, and Shahbudin Bin Saad ${ }^{2}$ \\ ${ }^{1}$ Remote Sensing, GIS, and Physical Oceanography Modelling Laboratory, Marine Science Department, Kulliyyah of Science, \\ International Islamic University Malaysia, Jalan Istana, Bandar Indera Mahkota, 25200, Kuantan, Pahang, Malaysia \\ ${ }^{2}$ Marine Tropical Ecosystem Laboratory, Marine Science Department, Kulliyyah of Science, International Islamic University Malaysia, \\ Jalan Istana, Bandar Indera Mahkota, 25200, Kuantan, Pahang, Malaysia \\ *Corresponding author: zuhairiahmad@iium.edu.my
}

\section{KEYWORDS}

3D

Coral Photogrammetry (CP)

Coral Video Transect (CVT)

Low-cost underwater camera

\begin{abstract}
This research analysed the use of 3D Coral Photogrammetry (CP) and Coral Video Transect (CVT) images collected from SCUBA divers using a low-cost underwater action camera to examine the coral lifeform. A comparison was made between data sets obtained using both methods on nine transects with different coral lifeform compositions and percentage cover within an area of $4 \times 7 \mathrm{~m}$. The comparison of the statistical analysis for CPCe revealed that there were no significant differences $(p<0.05)$ between CP and CVT photos where dead corals $(p=0.006)$, sand $(p=0.011)$, and unknown ( $p=0.002$ ) are present. Additionally, the coral value $(p=0.131)$ between CP and CVT was not significant. $\mathrm{CP}$ was capable of producing prominent branching, massive, and plate coral morphology results. This suggests that survey methods using low-cost action cameras for 3D Coral Photogrammetry would yield appropriate results in terms of coral lifeform detection. Hypothetically, by improving camera quality, it will yield a higher accuracy of 3D coral images that are suitable for use in scientific research and management. Other benefits of using CP include the possibilities for future studies with 3D coral surveys using remotely operated vehicles, less field time, and 3D coral seabed information.
\end{abstract}

(c) The Author(s) 2020. This article is distributed under a Creative Commons Attribution-ShareAlike 4.0 International license.

\section{INTRODUCTION}

Scientists have used several different approaches in the past to observe behaviour, measure the abundance, or analyse corals' wellbeing. One of the rising approaches being practiced is Coral Video Transect (CVT). CVT's advantages include having a permanent record, less sampling time required, simple performance, and no need for on-site knowledge detection (Chark et al. 2012). Conversely, CVT has some disadvantages, such as it being difficult to recognize two-dimensional coral development, and a lack of real-size detail of coral colonies (Hill and Wilkinson 2004). With the current advancement of technology, methods for coral surveying using photogrammetry and three-dimensional imagery technologies have been introduced, which aid in the analysis of coral growth and health, comprehensively. Photogrammetry is characterized as technology or science for obtaining reliable information about physical objects and the environment through recording, measuring, and interpreting processes of photographic images and patterns of electromagnetic radiant energy (Aber et al. 2010). It is also known as Structure from Motion where it is a tool used to process a series of two-dimensional images or videos into specific three-dimensional models that stitch together on similar defined points (Raoult et al. 2016). Thus, this would that the time taken for survey with research to be performed afterwards, along with study that believed not only for coral abundance, but also the characteristics of coral reef health and taxonomy. This technology also communicates much easier and conveniently with people via $3 \mathrm{D}$ visualization for subsequent retrieval of the data. Thus, this study aimed to evaluate the 3D Coral Photogrammetry $(\mathrm{CP})$ methods for coral lifeform analysis in comparison with Coral Video Transect (CVT), as well as to establish best practices and design in the development of quality stereo images. In addition, this study assessed, for this reason, the reliability of the low-cost underwater action camera.

\section{MATERIALS AND METHODS}

\subsection{Research area}

The research was conducted at one sampling point (Figure 1) in the nearshore region facing Salang Village beach, Tioman Island. Tioman Island has a high biodiversity of corals, with 65 genera reported and dominated by the genera Acropora, Montipora, and Porites, most of which are in good health (Shahbudin et al. 2017; Reef Check Malaysia 2017; Hill and Wilkinson 2004).

\subsection{Camera and frame designs}

The frame material consisted of several $40 \mathrm{~cm}$ Polyvinyl Chloride (PVC) pipes connected to form a frame structure. Several designs were drafted, tested, and analysed for their suitability and compatibility. Regarding camera location, the main camera was located in the middle of the frame 


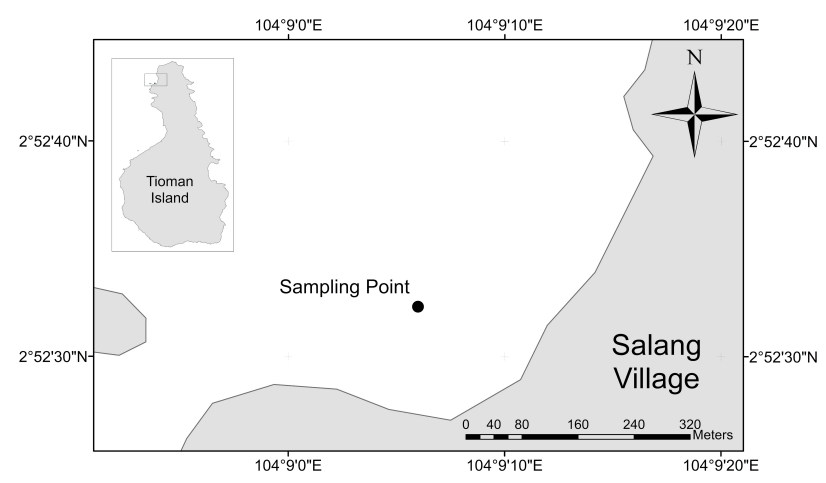

FIGURE 1. Location of sampling point $\left(02^{\circ} 52^{\prime} 32.38^{\prime \prime} \mathrm{N}, 104^{\circ} 09^{\prime} 06.08^{\prime \prime} \mathrm{E}\right)$ at Salang Village, Tioman Island.

recording planar video, while other action cameras were mounted on the side of the frame and angled $45^{\circ}$ inwards, allowing for multiple angled video recordings on the side, as shown in Figure 2 (Ferrari et al. 2017). The action cameras' $45^{\circ}$ angle enabled four separate perspectives of vertical coral to enhance the quality of 3D images. The four EKEN H9R action cameras were mounted on four sides of the PVC frame, with an Olympus TG4 in the middle of the frame, serving as the main camera. The TG4 was set to the standard setting-for both land and underwater sampling, without white balance, to minimize inconsistencies from the picture taken from the TG4 to the action cameras. The research took part in cinematography, allowing for a high number of continuous images to be collected from overlapping images (Cocito et al. 2003).

\subsection{Coral model setup}

A coral model test consisting of PVC modelled as branching coral, and rigid rocks representing brain and tabletop coral, was performed. The research was conducted in two ways: by taking images at all angles around a coral model, as shown in Figure 3, and recording coral videos in planar and $45^{\circ}$ angle movement. The research was also performed subsequently on mixed bleached corals using the same two methods. Furthermore, the experiment was carried out on a grassy area to imitate the natural coral reef setting.

\subsection{Field test and image acquisition}

A second test was performed at the sampling site, which involved SCUBA diving between depths of 3 and $5 \mathrm{~m}$. On coral reefs, transect area sizes of $7 \times 4 \mathrm{~m}$ were built. The first sampling was performed by capturing coral images with a time lapse of one picture every $2 \mathrm{~s}$ (Ferrari et al. 2017), and the second sampling was performed using the CVT method of survey. The diver moved at a constant velocity and in a zig-zag direction to obtain an overlapping coral image and

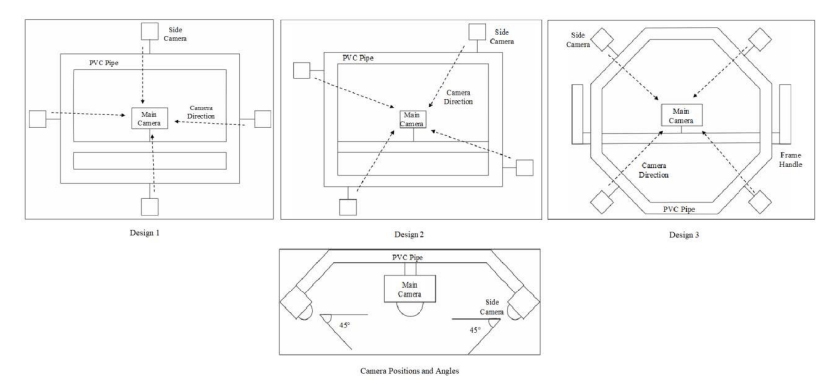

FIGURE 2. Suggested frame designs with angles and positions. picture. As the camera moves above the coral colony, for a better 3D reconstruction, about 5-10 images should overlap roughly $60-80 \%$ (Ferrari et al. 2017; Raoult et al. 2016). The distance between the diver and coral should be approximately $1 \mathrm{~m}$, where being too close to the coral can result in a blurred image and less area of the coral being covered by the photos.

\section{$2.53 \mathrm{D}$ reconstruction and image analysis}

From the video recorded during the second sampling, the sequence of images that overlapped were extracted into nine transects, according to the number of transect lines laid. The Agisoft Photoscan 1.4.0 software was then used to perform the analysis of the images collected during the first and second tests. Beginning with the first transect, all transect per one sequence of images from all four action cameras were inserted and placed into the workspace. The alignment method eventually acquired a core point that overlapped images and specified the position and orientation of the images (Burns et al. 2015). Then, several steps were used to process the aligned images to create a dense cloud, mesh, texture, and tiled layer, resulting in a 3D coral layer. The process was repeated for the other transects. In the end, all the transects were aligned and fused, creating a coral bed region of $7 \times 4 \mathrm{~m} 3 \mathrm{D}$. The acquired 3D data was then analysed in the CPCe 4.1 software (Kohler and Gill 2006) for identification and comparison with 2D CVT data, in terms of life type, species, and other parameters. Performing CPCe requires several images from video and the 3D coral bed area taken from similar transect. Therefore, coral identification was carried out for both CVT and 3D. Using coding for each parameter, every image from six selected transects of both 2D and 3D were identified, as each image as assigned with 30 points, randomly. Then, the percentage coverage of all categories was compared between 2D and 3D images. From the CPCe data, results of each transects were also compiled and compared between 2D and $3 \mathrm{D}$ images in terms of similarity and accuracy, by percentage cover and performing statistical analysis using a Paired T-Test. The Paired T-Test was selected due to the comparison of similar elements (Coral Area) with different methods (2D/3D). The data were compared in terms of healthy coral, dead coral, sand , and unknown categories, between the 2D and 3D data.

\section{RESULTS AND DISCUSSION}

\subsection{D image production}

In this study, the ability of generating 3D images from stereo image pairs was confirmed with several earlier tests that were conducted both on land and in water (Figure 4).

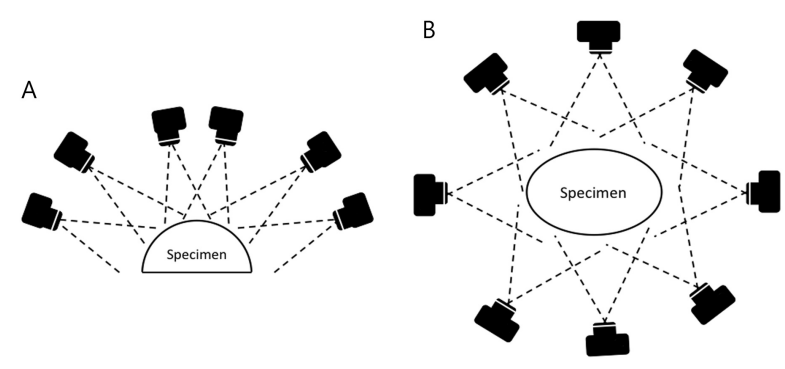

FIGURE 3. Camera setup to capturing all directions and angles of model (House et al. 2018). 


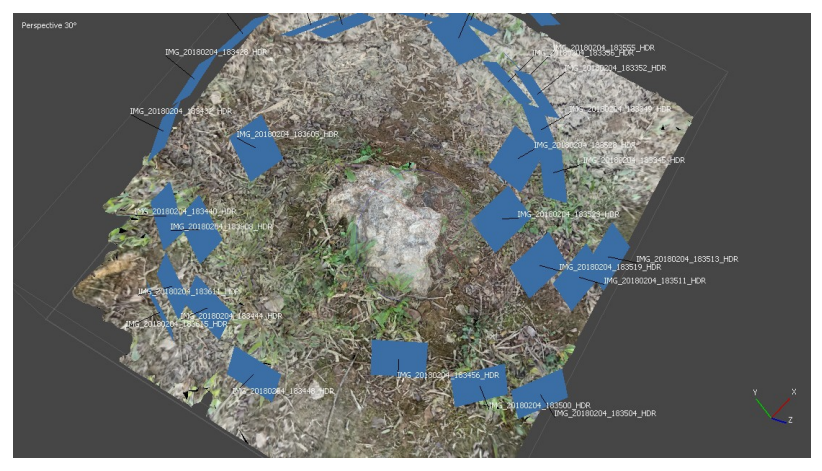

(a)

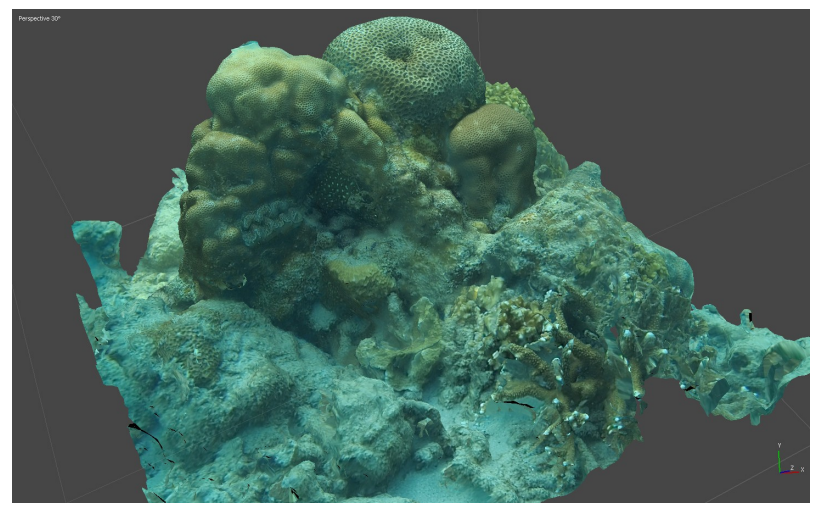

(b)

FIGURE 4. Test results on (a) rock on land, and (b) coral underwater.

From the test, the possibility of producing 3D images was proved with a much higher chance when the surrounding of the sample has some noise, such as grass and soil that helps in identification and selection of similar points from several images. Figure $4 \mathrm{~b}$ shows a good 3D image of the coral patch acquired from field sample data. The higher the number of images used, the better the 3D quality. In addition, the quality can be further improved by taking several images of the sample from various distances, creating more detail in the 3D image. These testing results indicate the high possibility for 3D image production for corals. With this, the first objective of this study has been fulfilled.

\subsection{Frame design}

The best design that was chosen for the frame, as shown in Figure 2, was one with an octagonal shape (Design 3), where the main camera is in the middle and four side cameras are located at the edge of the frame, the latter with a $45^{\circ}$ angle inwards. This design is optimized with respect to the direction in which each camera will capture overlapping images from four different points of view, at $45^{\circ}$ angles directed towards the subject in the middle of the frame. It also enables better movement for the diver during recording. Unfortunately, the third frame design cannot be produced due to the limitation of PVC connectors in the octagonal formation shape. Therefore, this study proceeded with the second frame design, where side cameras of EKEN H9R are located at the edge of PVC sides, with all side cameras facing towards the main camera in the middle, that camera being an Olympus TG4 (Figure 2). The ultimate appearance of this design will be that shown in Figure 5. While the final design used in this study and the optimal design were different, the quality of 2D images and production of the 3D model was not affected.

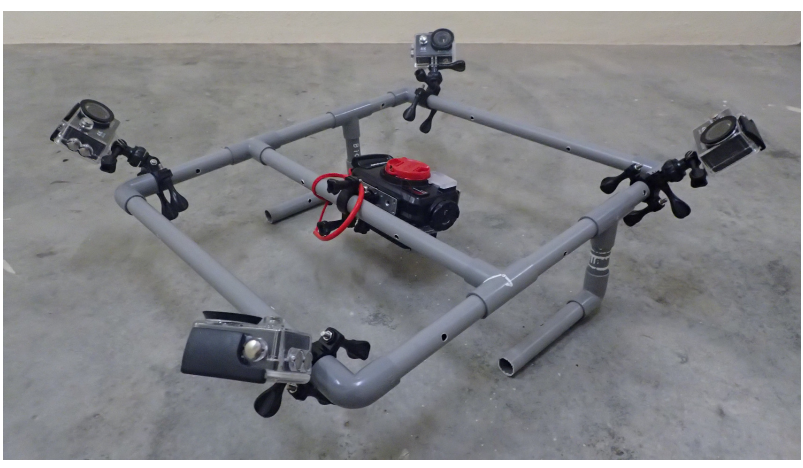

FIGURE 5. Final product based on the second prototype frame design with all cameras mounted.

\subsection{Production of 3D coral reef}

As the possibility of coral 3D production was confirmed, all of the images from the nine transects were processed transect-by-transect, and then merged to form a bed of coral reef (Figure 6). All of the images were processed in batches, which allowed for quicker processing time to create transects, and were finally merged together to form one large coral bed. Processing all of the images in one batch is possible and better, but takes a longer time to match the images and render them as a 3D model. Unfortunately, there is a downside of merging by transects, where sometimes some transects will not be equally similar in terms of overall colour and quality, making some areas seem like they are overlapping and redundant. On the positive side, merging allows covering up at some blank areas where redundancy with other transects occurs.

\subsection{Comparison between 2D and 3D coral}

Regarding the quality of both image types, 3D images were quite similar to 2D images. However, 3D was much better in terms of coverage where one image of an area in 3D could comprise up to two 2D images of a different area located near and around it. Furthermore, production from 3D enables observing of both the side and planar views of coral (Table 1). 3D was able to produce good images of tubular, massive, and sub-massive corals, such as those belonging to the genera Favites, Goniastrea, and Porites. For branching and plate corals, the 3D image just showed the whole colony, not as per figure of the branches, due to distortion. With the difficulty in observing and identifying branching and plate corals, this problem can be traced back to the lowend equipment being used, namely the EKEN H9R action camera. The camera itself has the capability to be used for coral surveys. However, its performance and image qual-

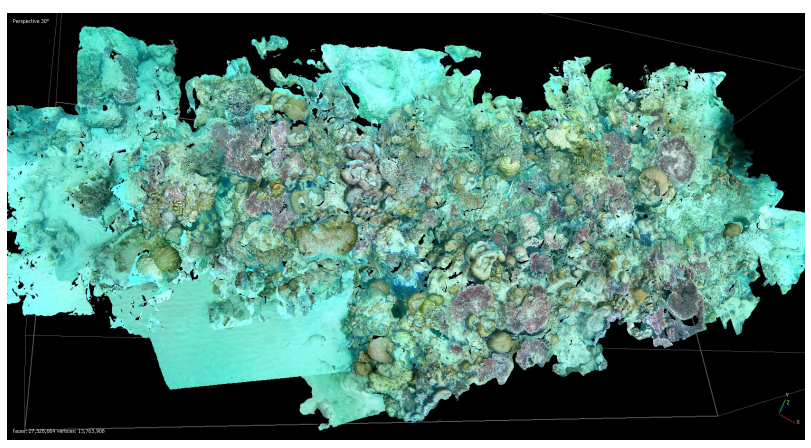

FIGURE 6. Overall combination of transects into 3D coral bed model. 
ity do not solve the problem of producing good 3D images. Therefore, in order to produce better results, higher or better cameras should be used, which can produce much more accurate and high quality $2 \mathrm{D}$ images. The processing issue also plays a huge role in producing quality $3 \mathrm{D}$ images. As Table 1 shows, the differences between the 2D (CVT) images and 3D images taken from the model appear to be low. That said, not all 3D images show a total similarity to the 2D images, as some branching and plate areas were facing distortion. For other coral morphologies, like massive and tubular corals, there wasn't a distortion problem as that displayed with branching coral. The distortion also can occur when one area doesn't have enough overlapping of images, making it blank or stretched.

\subsection{Statistical analysis}

The 3D images were analysed in terms of genus and lifeform of coral. The main categories that were included in the analysis were the coral, algae, soft coral, gorgonian, dead coral, sand, pavement and rubble, unknown, and four other classes. Meanwhile, the subcategories consisted of 83 genera of coral, including Acropora, Favites, Goniastrea, Stylo- pora, and others. The categories also included the eight coral morphologies: branching, encrusting, foliose, isolate, massive, plate, and sub-massive. The results of CPCe analysis showed that both $3 \mathrm{D}$ and $2 \mathrm{D}$ coral beds had a high percentage of massive corals, followed by branching, plate, and sub-massive corals, while only about $3 \%$ of corals were identified as tubular, foliose, and isolated. The percentage of coral morphology between the 3D and 2D images can be said to be similar or closer to each other, where it indicates a relative similarity between the $3 \mathrm{D}$ and $2 \mathrm{D}$ results.

The most prominent genus identified was Acropora, followed by Favites, Goniastrea, and Psammocora, which made up most of the massive and sub-massive corals. Comparing the 3D and 2D images, Favites and Psammocora were found in a slightly higher percentage in 3D than 2D. Conversely, for Acropora, Goniastrea, and other corals, the values were higher in 2D than 3D. From these results, 3D images have shown the capability to produce good coral images from massive lifeforms like Favites and Psammocora, while 2D images are better for branching corals like Acropora.

Mostly, the points identified from the coral bed with a high percentage were sand and rubble, followed by dead

\begin{tabular}{lll}
\hline $2 D$ images & $3 D$ images \\
\cline { 2 - 4 } & $90^{\circ}$ (planar view) & $45^{\circ}($ side view) \\
\hline
\end{tabular}
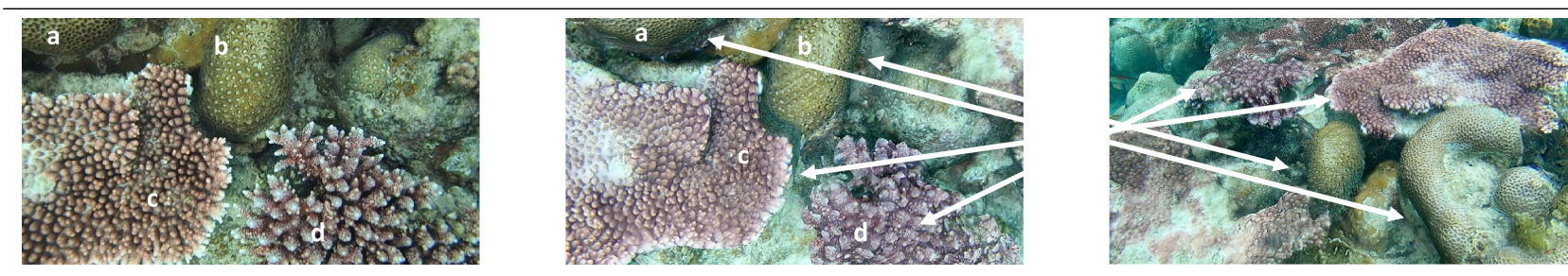

a - Favites, b - Favia, c - Acropora (P), d - Acropora (B)
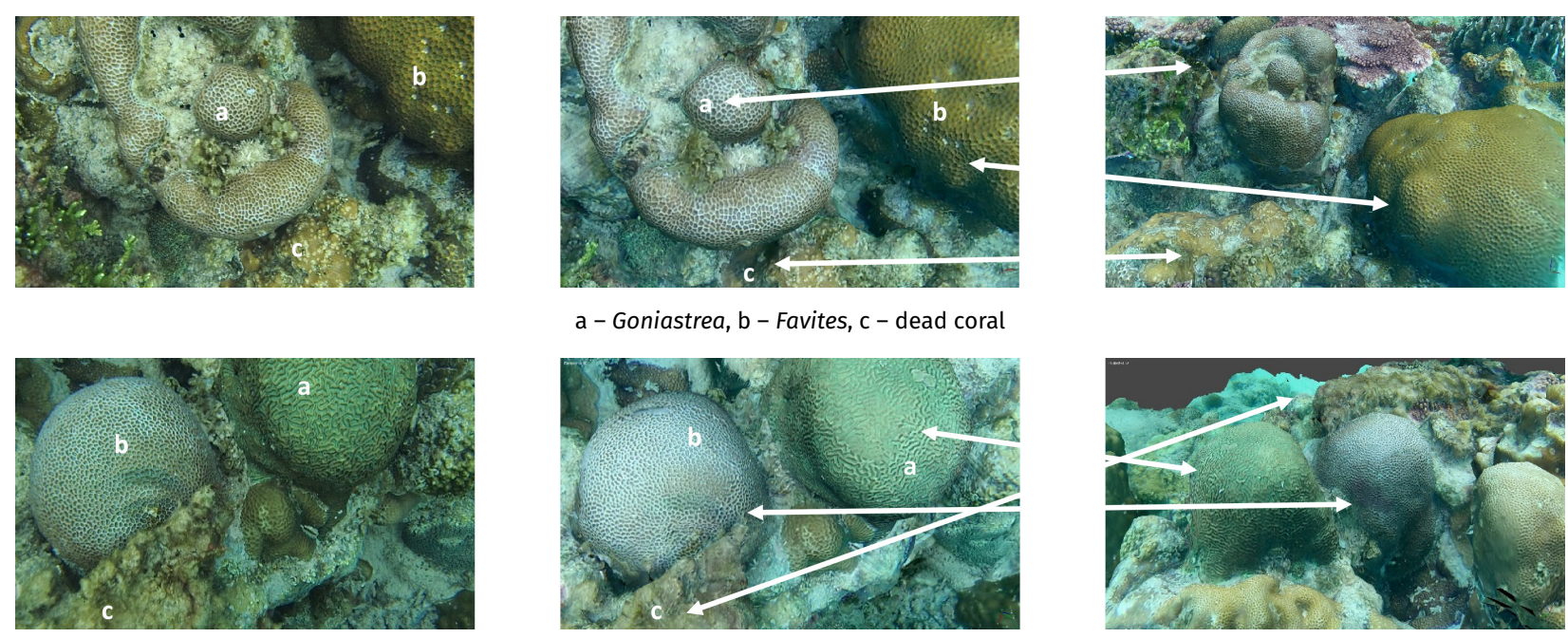

a - Goniastrea, b - Favites, c - dead coral
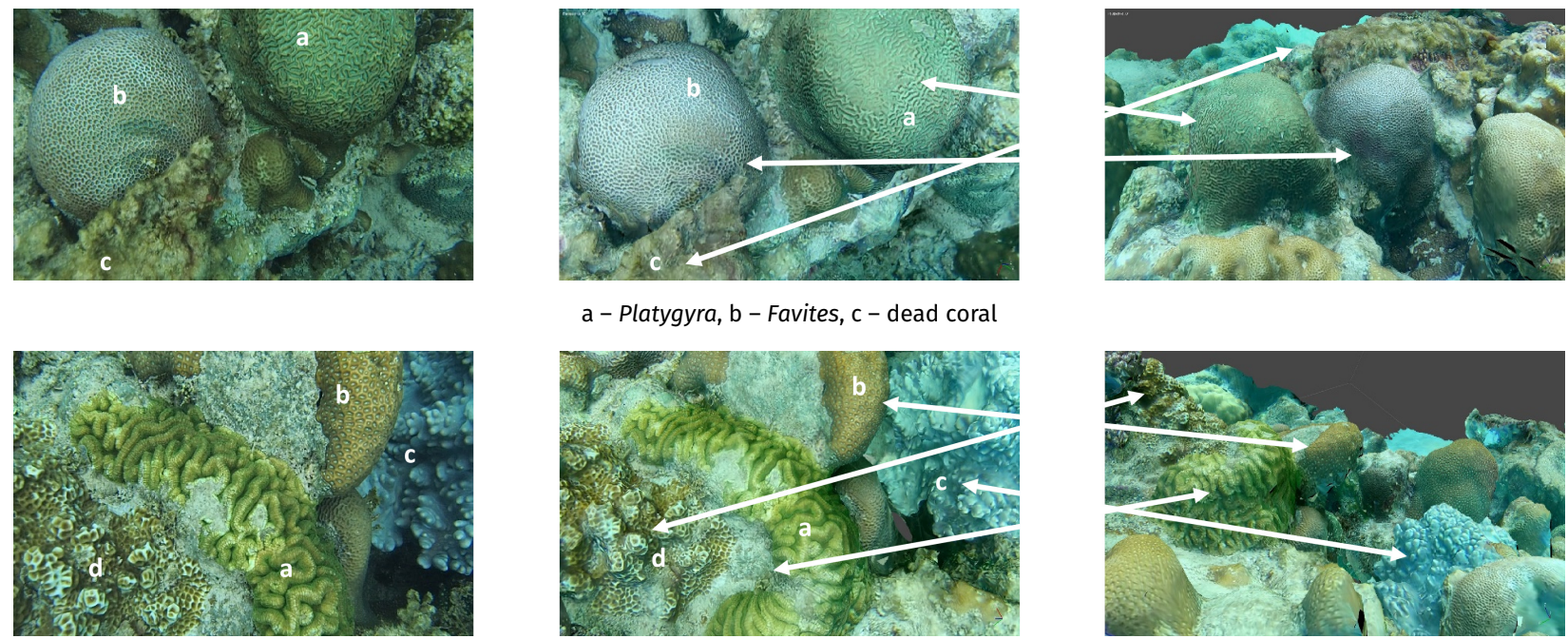

a - Platygyra, b - Favites, c - dead coral
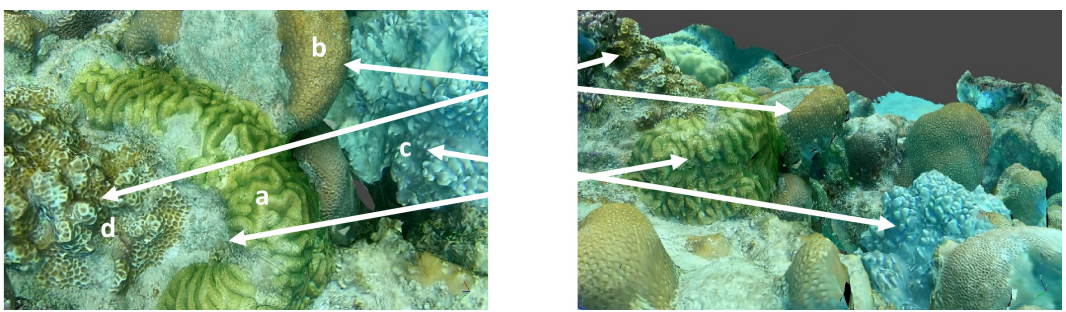

a - Lobophyllia, b - Favites, c - Stylopora, d - Goniastrea 


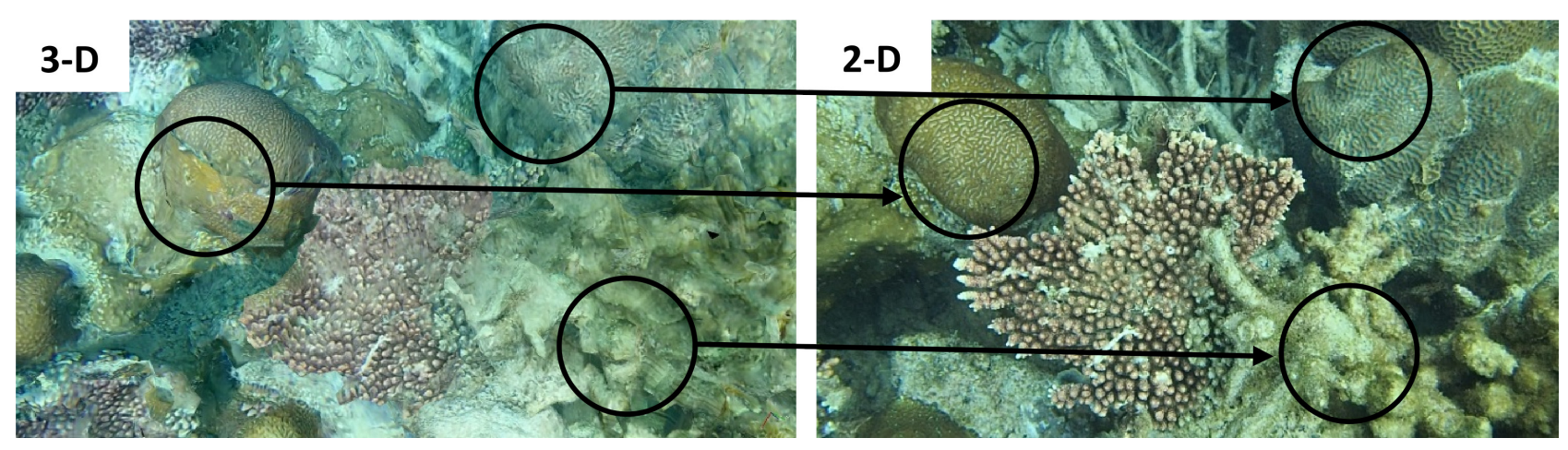

FIGURE 7. Distortion on 3D massive coral image compared with 2D image.

coral with about $24 \%$ and $14 \%$ in $3 \mathrm{D}$, and $19 \%$ for both in $2 \mathrm{D}$, respectively. This indicates that $3 \mathrm{D}$ has good potential in expressing features that aren't complex and simple, like sand and rubble, and massive coral, instead of complex and repetitive structures, such as branching coral. The percentage can be further analysed in terms of the unknown parameter, where 3D indicates about 5\% unidentified points compared with $2 \mathrm{D}$, which was about $2 \%$ only. Comparing 2D and 3D in terms of unknown data, the results showed about a similar number of points cover, but the unknown or unidentified points were much more prominent in the 3D images, due to the distortion factor.

With the collected data, Paired T-Test statistical analysis was used to identify the differences between the results of the 2D and 3D images. From the CPCe data, the results from the parameters of coral, dead coral, sand and rubble, and unknown were compared using Paired T-Test analysis. The results revealed that the mean of healthy coral and dead coral cover for 2D was much higher than 3D, whereas sand and unknown cover were much higher for 3D than 2D. Comparing the mean between the samples, the results indicated that coral and dead coral in the 2D images were higher than the 3D images, with values of 57.75 to 54.92 and 19.27 to 14.41 , respectively. Sand and rubble and unknown means for 3D were higher than $2 \mathrm{D}$, with values of 23.98 to 18.69 and 5.21 to 1.59 , respectively. From that, the correlation between 2D and 3D in terms of the coral and dead coral parameters was found to be high, with values of 0.699 and 0.730 , respectively, which indicates a link between the 2D and 3D data. However, for the sand and rubble and unknown parameters, there was not much correlation between 2D and 3D as the values were lower, at 0.559 and 0.210 , respectively.

As for the results from the Paired T-Test, the significant level for 2D and 3D coral cover pair was exceeding 0.05 ( $p$ $>0.05$ ), which indicates that the $2 \mathrm{D}$ and $3 \mathrm{D}$ healthy coral cover identified was not significant, with a value of 0.131 . This value suggests that the $3 \mathrm{D}$ images were not equal to or much better than the 2D images. Meanwhile, for the dead coral pair, sand and rubble pair, and unknown pair results, a different story was found, with a significant difference as the values were below $0.05(p<0.05)$, at $0.006,0.011$, and 0.002 , respectively. This results in the $3 \mathrm{D}$ images being equally similar to the 2D images in terms of dead coral, sand and rubble, and unknown parameters. Therefore, these results have confirmed the hypothesis, where the 3D surveying method can identify corals up to the genus level, albeit not as well as the CVT method. The Objectives of this study, in term of statistical analysis, have confirmed that 3D data were neither similar nor better than 2D data, owing to the factor of 3D image distortion.
The distortion of 3D images formed during 3D modelling was due to $2 \mathrm{D}$ images and processing machine issues. This distortion is believed to contribute to the difference in coral over data between the 3D and 2D images as the analyser could not identify the distorted points, thus marking them as unknown. The reason behind this issue is due to difficulty faced by Agisoft Photoscan in differentiating repetitive forms occurring in branching corals. The processing machine cannot maintain a high performance of the software due to deficiencies in the graphics card, processor, and memory. Furthermore, the occurrence of the distortion could also be an issue related to unfocused and blurry of images combined during the stitching process of the 3D model. Thus, lacking good, accurate, and sharp images or videos of 2D coral not only distorts 3D branching coral, but also affects a small number of 3D images of massive coral (Figure 7).

\section{CONCLUSIONS}

In conclusion, the study was successfully conducted. The photogrammetry method showed the capability to produce a 3D model of a coral reef, by using best practices and design that have been introduced. The data between 3D and $2 \mathrm{D}$ were also compared, with $3 \mathrm{D}$ results similar to the $2 \mathrm{D}$ results in terms of massive and plate coral, but not for branching coral. This study also proved that 3D modelling and imaging of coral reefs is capable in monitoring and surveying activities. In terms of quality, coral $3 \mathrm{D}$ modelling can identify a coral reef up to the genus and morphology as well as CVT, although this identification can be conducted with high accuracy for massive, sub-massive, isolate, and tubular lifeforms, but not for branching and plate coral forms. Statistically, this study showed that 3D images are not equal to 2D images, but closely reach the quality of $2 \mathrm{D}$ images. Thus, this refutes the hypothesis of coral 3D modelling as a replacement of the CVT method of surveying, for now. With more improvements on processing units and camera specifications, coral 3D modelling can be used to replace the current survey method of CVT, with much better results. Additionally, 3D modelling can help to introduce coral reef ecosystems to people who are unable to directly monitor and interact with the reef, along with making it easier for researchers to analyse it.

\section{ACKNOWLEDGMENTS}

The authors wish to express their gratitude to the team of Remote Sensing, GIS, and Physical Oceanography Modelling Laboratory, Kulliyyah of Science, International Islamic University Malaysia (IIUM) and INOCEM Research 
Centre, for technical assistance and logistics throughout the sampling period. This research was been funded by a private organization in collaboration with IIUM (Bayu Tinggi/2019/CSR/IIUM/69A).

\section{AUTHORS' CONTRIBUTIONS}

ZA, MIHMJ and SS conceived the ideas; ZA and MIHMJ designed the methodology and collected the data; MIHMJ analysed and interpreted the data; ZA and MIHMJ led the writing of the manuscript. All authors contributed critically to the drafts and gave final approval for publication.

\section{COMPETING INTERESTS}

The authors declare no competing interest.

\section{REFERENCES}

Aber JS, Marzolff I, Ries JB. 2010. Small-format aerial photography: principles, techniques and geoscience applications. Amsterdam: Elsevier.

Burns JHR, Delparte D, Gates RD, Takabayashi M. 2015. Utilizing underwater three-dimensional modeling to enhance ecological and biological studies of coral reefs. Int Arch Photogramm Remote Sens Spatial Inf Sci. XL5/W5:61-66. doi:10.5194/isprsarchives-XL-5-W5-61 -2015 .

Chark LH, Siang HY, Bachok Z, Wagiman S, Ibrahim K, Said A, Chan AA. 2012. A guide to collecting digital videos for coral reef surveys and monitoring purposes. Kuala Lumpur: Department of Marine Park Malaysia.

Cocito S, Sgorbini S, Peirano A, Valle M. 2003. 3-D reconstruction of biological objects using underwater video technique and image processing. J Exp Mar Biol Ecol. 297(1):57-70. doi:10.1016/S0022-0981(03)00369-1.
Ferrari R, Figueira WF, Pratchett MS, Boube T, Adam A, Kobelkowsky-Vidrio T, Byrne M. 2017. 3-D photogrammetry quantifies growth and external erosion of individual coral colonies and skeletons. Sci Rep. 7(1):1-9. doi:10.1038/s41598-017-16408-z.

Hill J, Wilkinson C. 2004. Methods for ecological monitoring of coral reefs: a resource for managers. Townsville: Australian Institute of Marine Science. https://gcrmn. net/wp-content/uploads/2018/04/GCRMN_Ecolo gical_monitoring.pdf.

House JE, Brambilla V, Bidaut LM, Christie AP, Pizarro O, Madin JS, Dornelas M. 2018. Moving to 3D: relationships between coral planar area, surface area and volume. PeerJ. 6:e4280. doi:10.7717/peerj.4280.

Kohler K, Gill S. 2006. Coral Point Count with Excel extensions (CPCe): a Visual Basic program for the determination of coral and substrate coverage using random point count methodology. Comput Geosci. 32(9):12591269. doi:10.1016/j.cageo.2005.11.009.

Raoult V, David PA, Dupont SF, Mathewson CP, O'neill SJ, Powell NN, Williamson JE. 2016. GoPros ${ }^{\mathrm{TM}}$ as an underwater photogrammetry tool for citizen science. PeerJ. 4:e1960. doi:10.7717/peerj.1960.

Reef Check Malaysia. 2017. Status of coral reefs in Malaysia, 2016. Kuala Lumpur: Reef Check Malaysia. https://st atic1.squarespace.com/static/5c9c815e348cd94acf3 b352e/t/5d035875fbd7100001ea1714/1560500363157 /2016+Annual+Survey+Report.pdf.

Shahbudin S, Fikri Akmal K, Faris S, Normawaty MN, Mukai Y. 2017. Current status of coral reefs in Tioman Island Peninsular Malaysia. Turk J Zool. 41:294-305. doi:10.3 906/zoo-1511-42. 